\title{
ß3GnT8 Promotes Gastric Cancer Invasion by Regulating the Glycosylation of CD147
}

\author{
Li Shen ${ }^{1,2}$, Xiaoxia Dong33, Meiyun $\mathrm{Yu}^{2}$, Zhiguo Luo ${ }^{1,4}$, Shiliang $\mathrm{Wu}^{2}{ }^{凶}$ \\ 1. Department of Clinical Oncology, Taihe Hospital, Hubei University of Medicine, Shiyan 442000, Hubei, China \\ 2. Department of Biochemistry and Molecular Biology, Soochow University, Suzhou 215123, Jiangsu, China \\ 3. Department of pharmacology, School of Basic Medicine, Hubei University of Medicine, Shiyan 442000, Hubei, China \\ 4. Institute of Cancer Research, Taihe Hospital, Hubei University of Medicine, Shiyan 442000, Hubei, China
}

$\triangle$ Corresponding authors: Dr Shiliang Wu, Department of Biochemistry and Molecular Biology, Soochow University, No.1 Shizi Street, Suzhou 215123, Jiangsu, China; E-mail: shiliang_wu@126.com. Dr Zhiguo Luo, Department of Clinical Oncology, Taihe Hospital, Hubei University of Medicine, 30 South Renmin Road, Shiyan 442000, Hubei, China; E-mail: zhiguo_luo@163.com.

(C) Ivyspring International Publisher. This is an open access article distributed under the terms of the Creative Commons Attribution (CC BY-NC) license (https://creativecommons.org/licenses/by-nc/4.0/). See http://ivyspring.com/terms for full terms and conditions.

Received: 2016.06.18; Accepted: 2016.10.17; Published: 2017.02.05

\begin{abstract}
$\beta 1,3-\mathrm{N}$-acetylglucosminyltransferase $8(\beta 3 \mathrm{GnT})$ synthesizes a unique cabohydrate structure known as polylactosamine, and plays a vital role in progression of various human cancer types. However, its involvement in gastric cancer remains unclear. In this study, we analyzed the expression and clinical significance of $\beta 3 \mathrm{GnT}$ by Western blot in 6 paired fresh gastric cancer tissues, noncancerous tissues and immunohistochemistry on 110 paraffin-embedded slices. $\beta 3 \mathrm{GnT} 8$ was found to be over-expressed in gastric cancer tissues, which correlated with lymph node metastasis and TNM stage. Forced the expression of $\beta 3 G$ nT8 promoted migration and invasion of gastric cancer cells, whereas $\beta 3 \mathrm{GnT} 8$ knockdown led to the opposite results. Further studies showed that the regulated $\beta 3 \mathrm{GnT}$ 8 could convert the heterogeneous $\mathrm{N}$-glycosylated forms of CDI47 and change the polylactosamine structures carried on CD147. In addition, our data suggested the annexin A2 (ANXA2) to be an essential interaction partner of $\beta 3 \mathrm{GnT}$ 8 during the process of CDI47 glycosylation. Collectively, these results provide a novel molecular mechanism for $\beta 3 \mathrm{GnT} 8$ in promotion of gastric cancer invasion and metastasis. Targeting $\beta 3 \mathrm{GnT} 8$ could serve as a new strategy for future gastric cancer therapy.
\end{abstract}

Key words: $\beta 3 \mathrm{GnT} 8, \mathrm{CD} 147$, invasion, gastric cancer, glycosylation

\section{Introduction}

Gastric cancer is one of the most common malignancies worldwide, particularly in Eastern Asia (Korea, Mongolia, Japan, and China) [1]. It is difficult to cure unless it is found at an early stage [2]. Owing to the lack of early detection markers and effective therapeutic strategies, it has often reached an advanced stage [3]. Most of gastric cancer patients die due to tumor recurrence and metastasis, and the 5 -year survival rate is only $20-40 \%$ [4]. Thus, it is urgently needed for an improved understanding of the molecular mechanisms contributing to gastric cancer invasion and metastasis.

$\beta 1,3-\mathrm{N}$-acetylglucosminyltransferase $8(\beta 3 \mathrm{GnT}$ ) exerts its activity on tetraantennary N-glycans and elongates polylactosamine chains [5]. Initially, it had been reported that $\beta 3 \mathrm{GnT}$ 8 was cloned as $\beta 3 \mathrm{GalT7}$ from a human lung cDNA library [6]. Subsequently, it was named $33 \mathrm{GnT} 8$ based on its position in a phylogenetic tree and enzymatic activity [5]. Hence, both $\beta 3$ GalT7 and $\beta 3$ GnT8 are authorized for this gene. It was indicated that $\beta 3 \mathrm{GnT}$ 8 expression in the cervix tumor tissues was obviously higher than that in normal tissues [7]. A correlation between $\beta 3 \mathrm{GnT} 8$ and metastatic potential has been proposed base on its markedly enhanced expression in tumors such as colorectal cancer [8] and gliomas [9]. In a human gastric cancer cell line AGS, the expression of matrix metalloproteinase-2 (MMP-2) could be regulated by 
$\beta 3 G n T 8$ [10]. In addition, the ability of $\beta 3 \mathrm{GnT} 8$ to mediate CD147 signal transduction pathway has been confirmed in a gastric cancer cell line SGC-7901[11]. However, the regulatory mechanisms and biochemical properties of $\beta 3 \mathrm{GnT} 8$ in gastric cancer invasion need further exploration.

In the present study, we demonstrated that B3GnT8 was not only increased in gastric cancer tissues, but also was associated with clinical features, such as lymph node metastasis and TNM stage. We also confirmed that $\beta 3 \mathrm{GnT}$ 8 promoted gastric cancer cell invasion by regulating the $\mathrm{N}$-glycosylation of CD147. Our findings provide novel insights into the crucial role of $\beta 3 \mathrm{GnT} 8$ in gastric cancer progression and suggest $\beta 3 \mathrm{GnT} 8$ as a potential target for the prevention of gastric cancer metastasis.

\section{Materials and Methods}

\section{Tissue samples}

110 human gastric cancer and 45 adjacent non-tumor tissues were collected from patients who underwent surgical resection between 2007 and 2014 at the Taihe Hospital, Hubei University of Medicine. These tissues were stored at $-80^{\circ} \mathrm{C}$ immediately after surgical removal. 6 paired fresh gastric cancer tissues and noncancerous tissues were also obtained from the Taihe Hospital and stored in liquid nitrogen until use. None of the patients had received radiotherapy or chemotherapy before surgery. A written informed consent was obtained from each patient involved in this study and the study protocol was approved by the ethics committee of Hubei University of Medicine. All the clinicopathological parameters including age, gender, differentiation status, lymph node invasion and TNM stage were retrieved from patients' medical records. Investigations involving humans have been performed in accordance with the principles of Declaration of Helsinki.

\section{Western blot analysis}

Total proteins were extracted from the gastric cancer tissues and cells using the standard methods [9]. Proteins were quantified using a BCA Protein Assay Kit (Pierce, Rockford, IL, USA). Then samples were separated by $10 \%$ SDS-PAGE and transferred to PVDF membranes. The primary antibodies were anti-33GnT8 (1:1000), anti-CD147 (1:500; Santa Cruz, CA, USA), anti-annexin A2 (ANXA2) (1:1000; Santa Cruz), and anti-GAPDH (1:1000; Santa Cruz). The specificity of $\beta 3 \mathrm{GnT} 8$ antibody has been verified in our previous study [7]. Bands on the membranes were visualized using an ECL detection kit obtained from Beyotime Institute of Biotechnology (Jiangsu, China).

\section{Immunohistochemical (IHC) staining}

Formalin-fixed, paraffin-embedded tissue specimens were cut into $4-\mu \mathrm{m}$ sections. Then sections were dewaxed in xylene and rehydrated through graded ethanols. To block endogenous peroxidase, $3 \%$ hydrogen peroxide in methanol was used. Sections were then incubated with the anti- $\beta 3 \mathrm{GnT} 8$ antibody (1:100) or $4 \mu \mathrm{g} / \mathrm{ml}$ biotinylated Lycopersicon esculentum agglutinin (LEL) (Sigma, St. Louis,MO, USA). After washing in phosphate-buffered saline (PBS), tissues were incubated with Horseradish peroxidase (HPR)-labeled goat anti-rabbit secondary antibody (Santa Cruz) or HRP-conjugated streptavidin (Sigma). Finally, the sections were visualized using diaminobenzidine and counterstain with hematoxylin (Beyotime Institute of Biotechnology). Sections were photographed on an Olympus photomicroscope (Inha, Japan). The degree of IHC staining was evaluated by two independent pathologists. Staining intensity was graded as " 0 " (negative), " 1 " (weak), " 2 " (moderate) and " 3 " (strong); staining percentage was graded as "0" $(<5 \%)$, “1" (5-25\%), “2” (25-50\%), “3" $(50-75 \%)$ or " 4 " $(>75 \%)[12]$. A final immunoreactivity scores (IRS) was calculated by multiplying the values of the staining intensity and staining percentage. The IRS value $>4$ was defined as high expression and IRS value $\leq 4$ as low expression. ImagePro Plus (Media Cybernetics, Silver Spring, MD, USA) was used to quantitatively score the tissue sections.

\section{Cell lines and transfection}

Human gastric cancer cell lines AGS and NCI-N87 were obtained from the American Type Culture Collection (ATCC, Manassas, VA, USA). SGC-7901 cell line was purchased from the Type Culture Collection of Chinese Academy of Sciences (Shanghai, China). Cells were cultured in RPMI-1640 (GIBCO BRL, Carlsbad, MD, USA) containing 10\% fetal bovine serum (FBS) (HyClone, Waltham, UT, USA) in a humidified atmosphere with $5 \% \mathrm{CO}_{2}$ at $37^{\circ} \mathrm{C}$. The pEGFP-C1 (Mock), pEGFP-C1- $\beta 3 \mathrm{GnT} 8$ (T8S), pSilencircle- $\beta 3 \mathrm{GnT} 8 \mathrm{Scr}$ (T8Scr), and pSilencircle- $\beta 3 \mathrm{GnT}$ 8 (T8Si) plasmids were constructed by our laboratory [9]. Transfection was performed using Lipofectamine 2000 (Invitrogen, Carlsbad, CA, USA). Cells were collected $48 \mathrm{~h}$ after transfection for other assays.

\section{RNA extraction and quantitative real-time PCR}

Total RNA from cultured cells was extracted using TRIzol reagent (Invitrogen). Reverse transcription of RNA was carried out using the reverse transcription kit (Invitrogen). Quantitative 
PCR was conducted using SYBR-Green Real-Time PCR Master Mix kit (Toyobo, Osaka, Japan) and an ABI detection system (Applied Biosystems, Foster City, CA, USA). The PCR primers were designed for 33GnT8 were 5'-GTCGCTACAGTGACCTGCTG-3' (forward) and 5'-GTCTTTGAGCGTCTGGTTGA-3' (reverse); for GAPDH were 5'-CCAACCGCG AGAAGATGA-3' (forward) and 5'-CCAGAG GCGTACAGGGATAG-3' (reverse). GAPDH was used as an internal control. The data were collected and analyzed using the comparative $\mathrm{Ct}$ (threshold cycle) method.

\section{Lectin flow cytometry}

Briefly, $5 \times 10^{5}$ cells were harvested with $0.25 \%$ trypsin, and permeabilized by $0.1 \%$ triton X-100 for 5 minutes at room temperature. Biotin-labeled LEL was added to a final concentration of $20 \mu \mathrm{g} / \mathrm{ml}$ and incubated at $37^{\circ} \mathrm{C}$ for $2 \mathrm{~h}$. Then phycoerythrin-conjugated streptavidin (Sigma) of 10 $\mu \mathrm{g} / \mathrm{ml}$ was used, and incubated for $1 \mathrm{~h}$ at $37^{\circ} \mathrm{C}$ in the dark. Fluorescent analyses were performed using a FACScan flow cytometer (Becton-Dickinson, Mountain View, CA, USA). Only live cells were established as gates.

\section{Lectin blot}

The protein samples were extracted, quantified and subjected to $10 \%$ SDS-PAGE as described for western blot analysis. After blocking with Carbo-Free Blocking Solution (Vector Labs, Burlingame, CA, USA), the membranes were incubated with $2 \mu \mathrm{g} / \mathrm{ml}$ of biotinylated LEL for $1 \mathrm{~h}$. Then HRP-conjugated streptavidin (Sigma) was used as a secondary antibody. The blots were developed using an ECL substrate solution.

\section{Cell migration and invasion assays}

Wound-healing assay was performed

to examine the migration rates of cultured cells. Briefly, the cell layer that reached confluence was scratched by a $20 \mu \mathrm{l}$ pipette tip. Then photographs were taken immediately (time zero) and $24 \mathrm{~h}$ after wounding. Cell migration was evaluated by measuring the difference in wound width. For cell invasion assay, cells in serum-free medium were plated on 24 well Transwell inserts (Corning Life Sciences, Tewksbury, MA, USA) precoated with Matrigel. Medium containing 10\% FBS was added to the lower chamber. After $24 \mathrm{~h}$ culture, the cells that have moved through the pores to the lower side were stained with eosin staining solution (Beyotime Institute of Biotechnology).Invasion was evaluated by counting the number of the invaded cells.

\section{Immunoprecipitation(IP)}

Total cell lysates were prepared with IP lysis buffer (10 mM Tris, $1 \%$ triton-X-100, $1 \mathrm{mM}$ EDTA, $100 \mathrm{mM} \mathrm{NaCl}$ and a mixture of protease inhibitors) as previously described [13]. IP of indicated protein was performed with a 1:80 dilution of antibody overnight at $4{ }^{\circ} \mathrm{C}$ with constant rotation. Antibody-protein conjugates were pulled down by incubating samples with $10 \mu \mathrm{l}$ of Sepharose A beads (Thermo Fisher, Rockford, IL, USA) for $4 \mathrm{~h}$ at $4{ }^{\circ} \mathrm{C}$. Finally, the beads were washed, boiled, centrifuged and the recovered samples were run on 10\% SDS-PAGE for western blot or lectin blot as described above.

\section{LC-MS/MS analysis}

Coomassie brilliant blue R-250 (Sigma) staining was performed to visually detect specific immunoprecipitated bands of $\beta 3 \mathrm{GnT}$ \% antibody. The bands were subjected to in gel digestion by trypsin(Sigma). Digested peptides were analyzed by nano-HPLC (Ultimate 3000, Dionex) coupled to a linear quadrupole ion trap-Orbitrap (LTQ Orbitrap $\mathrm{XL}$ )mass spectrometer (Thermo Fisher) equipped with a nano-ESI source[14]. A nonlinear gradient using 2\% $\mathrm{ACN}$ in $0.1 \%$ formic acid in water and $0.1 \%$ formic acid in $98 \%$ acrylonitrile was used with a flowrate of $250 \mathrm{nl} / \mathrm{min}[14]$. All measurements were performed in the positive-ion reflective mode at an accelerating voltage of $18 \mathrm{kV}$ and delayed-pulsed ion extraction [15]. All MS/MS data were analyzed using Mascot (Matrix Science, London, UK; version 2.3.01) and searched against the latest NCBI nr protein database [16].

\section{Statistical analysis}

Data from the statistical analysis represent the mean \pm standard deviation (SD) from at least three independent experiments. Statistical differences between the two groups were examined by Student's $t$-test. Analyses of $\beta 3 \mathrm{GnT} 8$ and polylactosamines expression with clinicopathologic parameters were performed using Fisher's exact test. $P<0.05$ was considered statistically significant. All tests were preformed by SPSS 16.0 software (SPSS Inc, Chicago, IL, USA).

\section{Results}

\section{$\beta 3 \mathrm{GnT8}$ is highly expressed in gastric cancer tissues}

We fist examined the expression of $\beta 3 \mathrm{GnT} 8$ using Western blot in 6 pairs of gastric cancer tissues and their corresponding nontumorous tissues. Gastric cancer tissues showed marked higher levels than did corresponding non-tumor tissues $(P<0.05$, Figure 1$)$. 
In order to investigate the clinical significance of $33 \mathrm{GnT} 8$ in gastric cancer progression, immunohistochemical (IHC) staining was used to observe the expression of $\beta 3 \mathrm{GnT} 8$ in 110 gastric cancer tissues. As expected, $\beta 3 \mathrm{GnT} 8$ was mainly localized in the cytoplasm of gastric cancer cells, and its expression was much more dominant in tumor tissues than that in neighboring non-tumor tissues (Figure 2). $33 \mathrm{GnT}$ is involved in the biosynthesis of polylactosamine chains. Using LEL staining, differential expression profiles of polylactosamines could be observed [17]. Polylactosamines were predominantly expressed in the membrane and cytoplasm of gastric cancer cells, and their expression was clearly higher in gastric cancer tissues (Figure 2).

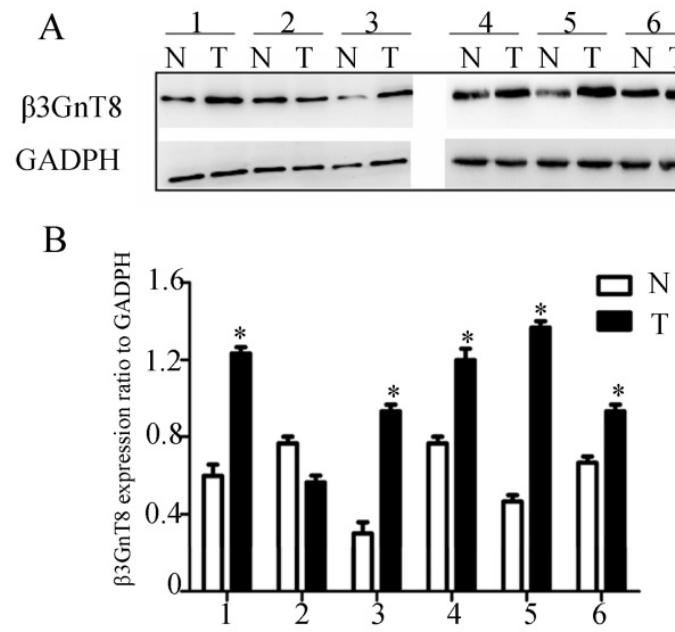

$71 \mathrm{kDa}$ $36 \mathrm{kDa}$

Figure 1. $\beta 3 \mathrm{GnT}$ 8 expression in human gastric cancer by western blot analysis. (A) The protein level of $\beta 3 G n T 8$ was high in 6 representative paired samples of gastric cancer tissue $(T)$ compared with nontumorous adjacent tissues $(N)$. GAPDH was used as a loading control. (B) The bar chart showed the ratio of $\beta 3 \mathrm{GnT} 8$ protein to GADPH. Bars represented mean \pm SD of three independent tests. $\left({ }^{*} P<0.05\right.$ compared with nontumorous adjacent tissues).

Then the relationship between $\beta 3 \mathrm{GnT}$, polylactosamine chains expression and clinicopathological features of gastric cancer was analyzed. As shown in Table 1, expression of $\beta 3 \mathrm{GnT} 8$ was correlated with the increased clinical stage $(P<0.05)$, depth of invasion $(P<0.05)$ and lymph lode metastasis $(P<0.05)$, but not statistically related to tumor differentiation, size, lauren classification, location or patients' gender and age. Polylactosamines were also closely related with lymph nodes metastasis $(P<0.05)$, depth of invasion $(P<0.05)$ and TNM staging $(\mathrm{P}<0.05)$, whereas no correlation with other clinicopathological factors. Furthermore, we found that $\beta 3 \mathrm{GnT} 8$ expression was positively correlated with polylactosamines expression in gastric cancer tissues $(P=0.003)$. These results suggest that $\beta 3 \mathrm{GnT} 8$ may be of diagnostic and/or prognostic value as a biomarker in gastric cancer.
Table 1. Relationship between $\beta 3 G n T 8$, polylactosamines expression and clinicopathological features of gastric cancer patients

\begin{tabular}{|c|c|c|c|c|c|c|c|}
\hline \multirow{2}{*}{$\begin{array}{l}\text { Clinicopathological } \\
\text { features }\end{array}$} & \multirow{2}{*}{$\mathrm{n}$} & \multicolumn{2}{|c|}{$\beta 3 \mathrm{GnT} 8$} & \multirow[t]{2}{*}{$P$} & \multicolumn{3}{|c|}{ polylactosamines $P$} \\
\hline & & \multicolumn{2}{|c|}{ High Low } & & High & Low & \\
\hline \multicolumn{8}{|l|}{ Age } \\
\hline$<60$ & 51 & 27 & 24 & 0.578 & 22 & 29 & 0.442 \\
\hline$\geq 60$ & 59 & 32 & 27 & & 28 & 31 & \\
\hline \multicolumn{8}{|l|}{ Gender } \\
\hline Male & 57 & 28 & 29 & 0.616 & 25 & 32 & 0.756 \\
\hline Female & 53 & 31 & 22 & & 26 & 27 & \\
\hline \multicolumn{8}{|l|}{ Tumor Size } \\
\hline$<5 \mathrm{~cm}$ & 45 & 15 & 30 & 0.341 & 25 & 20 & 0.139 \\
\hline$\geq 5 \mathrm{~cm}$ & 65 & 44 & 21 & & 32 & 33 & \\
\hline \multicolumn{8}{|l|}{$\begin{array}{l}\text { Lauren } \\
\text { classification }\end{array}$} \\
\hline Intestinal & 62 & 30 & 32 & 0.445 & 27 & 35 & 0.217 \\
\hline Diffuse & 48 & 29 & 19 & & 24 & 24 & \\
\hline \multicolumn{8}{|l|}{ Tumor location } \\
\hline Proximal & 8 & 4 & 4 & 0.329 & 3 & 5 & 0.221 \\
\hline Middle & 52 & 25 & 27 & & 23 & 29 & \\
\hline Distal & 50 & 30 & 20 & & 26 & 24 & \\
\hline \multicolumn{8}{|l|}{ Differentiation } \\
\hline Moderate-High & 69 & 39 & 30 & 0.188 & 33 & 36 & 0.168 \\
\hline Low & 41 & 18 & 23 & & 20 & 21 & \\
\hline \multicolumn{8}{|l|}{ TNM stage } \\
\hline $\mathrm{I}+\mathrm{II}$ & 47 & 28 & 19 & $0.013^{*}$ & 25 & 22 & 0.024 \\
\hline $\mathrm{III}+\mathrm{IV}$ & 63 & 50 & 13 & & 48 & 15 & \\
\hline \multicolumn{8}{|l|}{$\begin{array}{l}\text { Lymph node } \\
\text { metastasis }\end{array}$} \\
\hline Positive & 90 & 72 & 18 & $0.002^{*}$ & 65 & 25 & $0.011^{\prime}$ \\
\hline Negative & 20 & 17 & 3 & & 15 & 5 & \\
\hline \multicolumn{8}{|l|}{ Invasion depth } \\
\hline $\mathrm{T} 1+\mathrm{T} 2$ & 23 & 19 & 4 & $0.036^{*}$ & 15 & 8 & 0.024 \\
\hline $\mathrm{T} 3+\mathrm{T} 4$ & 87 & 68 & 19 & & 61 & 26 & \\
\hline
\end{tabular}

\section{$\beta 3 G n T 8$ promotes the migration and invasion of gastric cancer cells}

To further explore the role of $\beta 3 \mathrm{GnT} 8$ in gastric cancer, we screened three gastric cancer cell lines, AGS, SGC-7901 and NCI-N87 for its expression. Among the cell lines, AGS had the highest expression of $\beta 3 \mathrm{GnT} 8$ at both the mRNA and protein levels (Figure 3A). The expression of polylactosamines was also detected by flow cytometry with LEL (Figure 3B). Fluorescent intensity was computed as the median value of each staining. NCI-N87 cells showed lowest expression of polylactosamines, whereas AGS cells exhibited highest levels of polylactosamines. We therefore selected these two cell lines in the following experiments.

Then NCI-N87 cell line was transfected with a pEGFP-C1- $\beta 3$ GnT8 plasmid to over-express $\beta 3 \mathrm{GnT}$. AGS cell line was treated with a pSilencircle- $\beta 3 \mathrm{GnT}$ 8 plasmid to knockdown endogenous $\beta 3 \mathrm{GnT} 8$ expression. The effect of ectopic expression and knockdown of $\beta 3 \mathrm{GnT} 8$ in cells was confirmed by quantitative RT-PCR and western blot (Figure 3C).Compared with that of control cells, the migration 
and invasion abilities were markedly stimulated in NCI-N87 cells that over-expressing $\beta 3 G n T 8$ as indicated by wound-healing and transwell assays $(P<0.05$, Figure $3 \mathrm{D}$ and $3 \mathrm{E})$. Likewise, knockdown of $\beta 3 \mathrm{GnT}$ 8 could apparently repress the
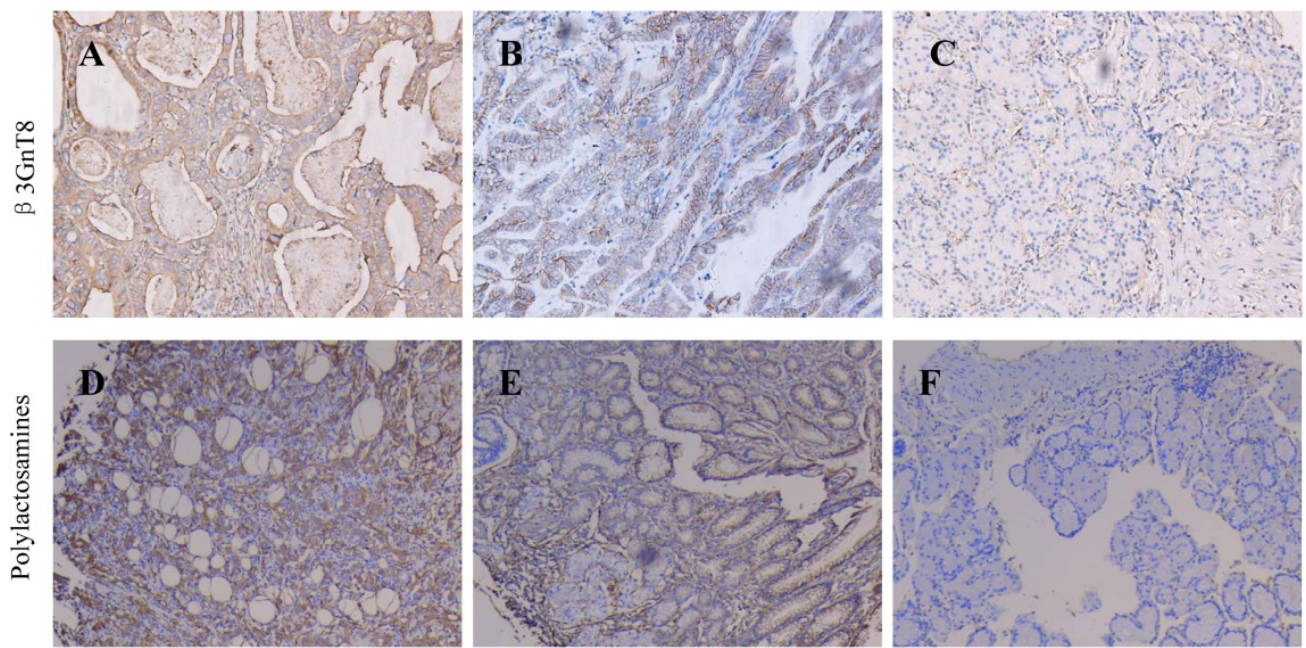

Figure 2. Immunohistochemical staining for the expression of $\beta 3 \mathrm{GnT} 8$ and polylactosamines in gastric cancer and adjacent non-tumor tissues ( $\times 200)$. (A) High positive $\beta 3 \mathrm{GnT} 8$ expression in gastric cancer. (B)Low positive $\beta 3 \mathrm{GnT}$ 8 expression in gastric cancer. (C) Negative $\beta 3 G$ nT8 expression in adjacent non-tumor tissues. (D) High positive polylactosamines expression in gastric cancer. (E)Low positive polylactosamines expression in gastric cancer. (F) Negative polylactosamines expression in adjacent non-tumor tissues.

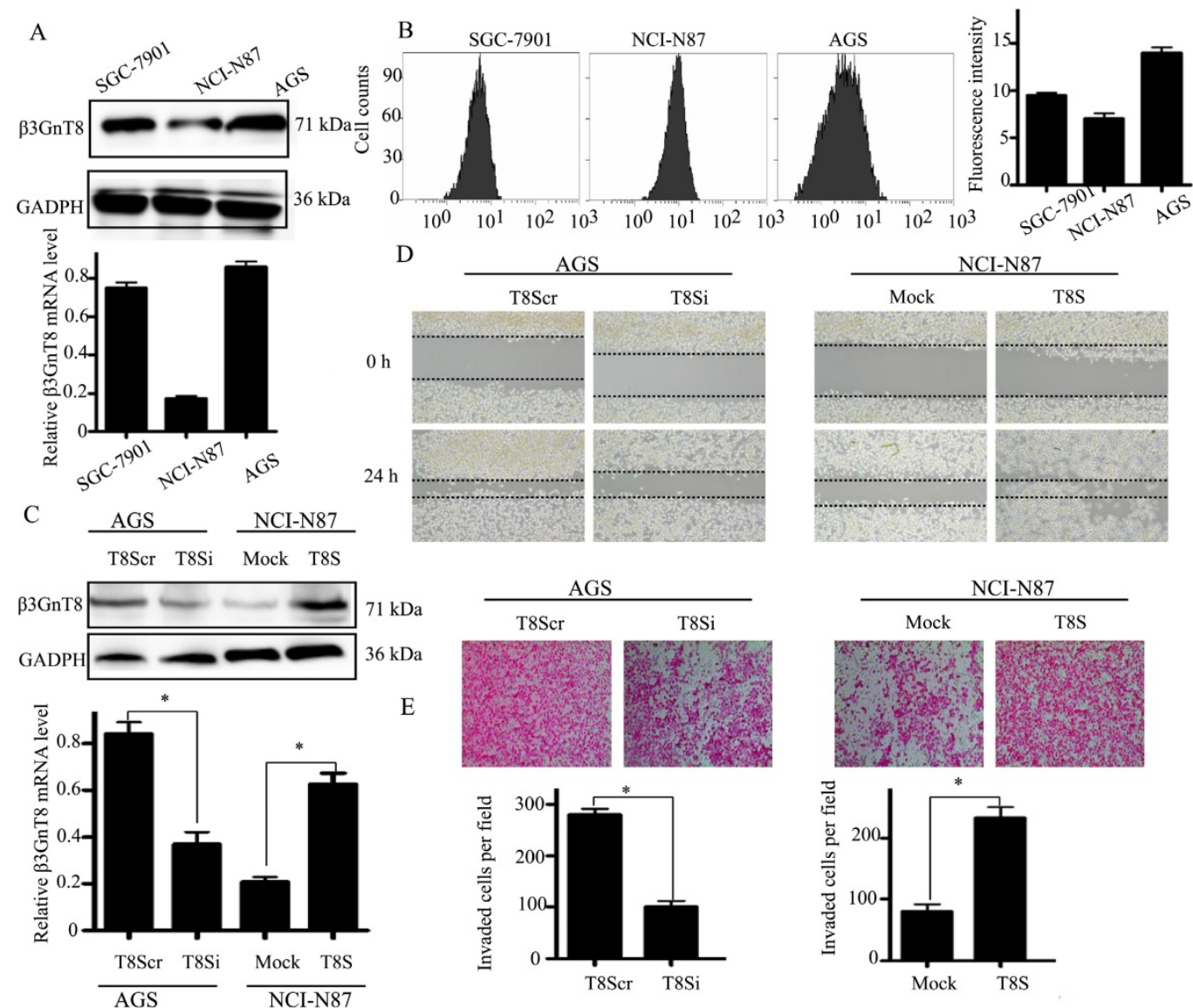

Figure 3. $\beta 3 G n T 8$ promotes gastric cancer cell migration and invasion. (A) Quantitative RT-PCR and western blot analysis of $\beta 3 \mathrm{GnT} 8$ expression in three gastric cancer cell lines. (B) Lectin flow cytometry analysis of polylactosamine expression in three gastric cancer cell lines. (C) The mRNA and protein levels of $\beta 3 G n T 8$ were detected by quantitative RT-PCR and western blot in NCl-N87 and AGS cells transiently transfected with pEGFP-C1 (Mock), pEGFP-C1- $\beta 3$ GnT8 (T8S), or pSilencircle- $\beta 3$ GnT8Scr (T8Scr), and pSilencircle- $\beta 3 \mathrm{GnT} 8$ (T8Si) vectors, respectively. (D) Wound healing assay with gastric cancer cells. Microscopic observations were recorded after scratching the cell surface $(200 \times)$. (E) Transwell assay with gastric cancer cells $(200 \times)$. Histograms showed the numbers of invasion cells. Bars represented mean \pm SD of three independent tests, all $* P<$ 0.05 . 


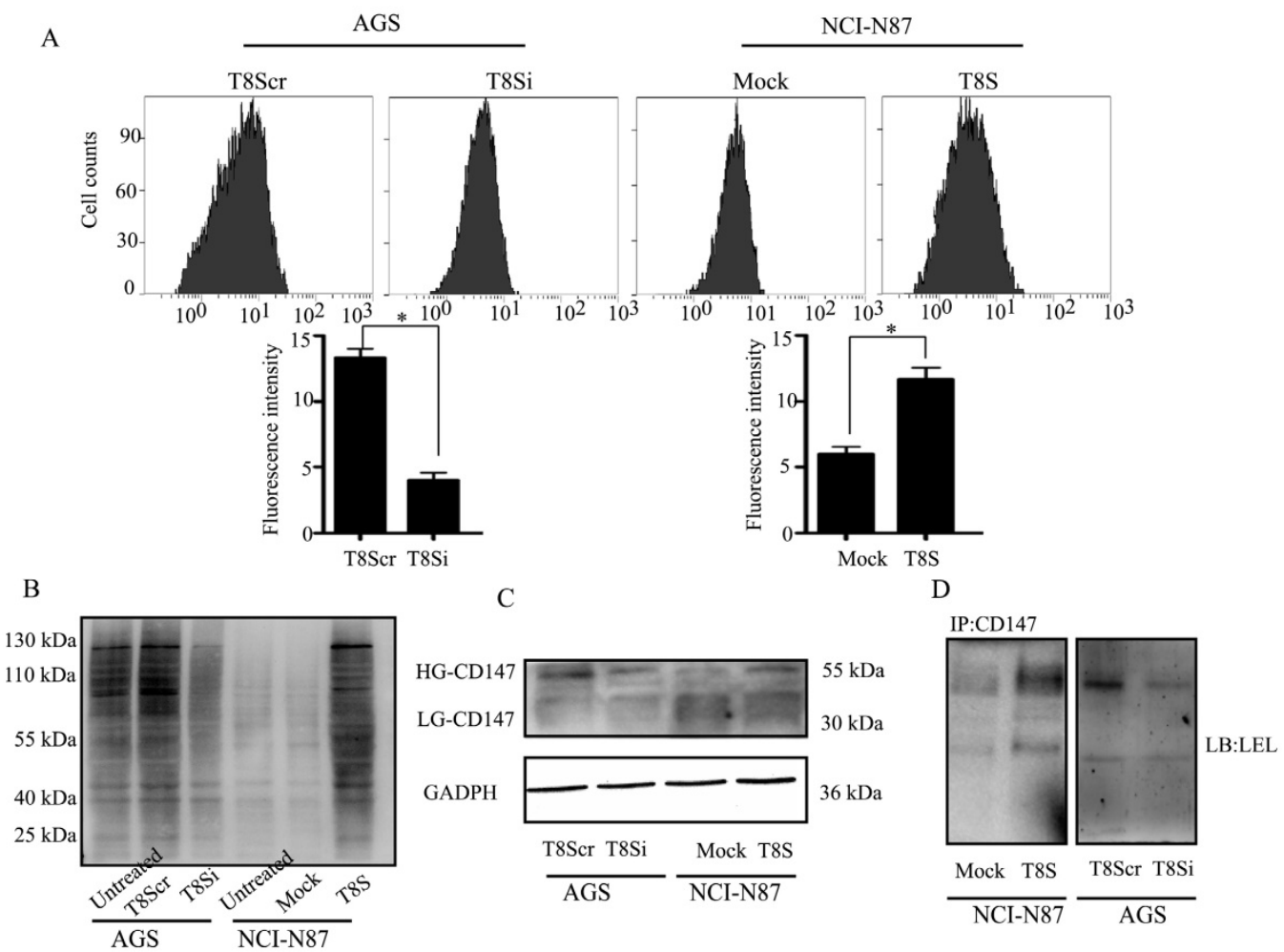

Figure 4. $\beta 3 \mathrm{GnT} 8$ regulates the $\mathrm{N}$-glycosylated forms of CD147 in gastric cancer cells. (A) Lectin flow cytometry analysis of polylactosamine expression in NCl-N87 and AGS cells transiently transfected with pEGFP-C1 (Mock), pEGFP-C1- $\beta 3$ GnT8 (T8S), or pSilencircle- $\beta 3 G n T 8 S c r$ (T8Scr), and pSilencircle- 33 GnT8 (T8Si) vectors, respectively. (B) Lectin blot assay with gastric cancer cells. (C)Western blot analysis of CD 147 glycosylation in gastric cancer cells. (D)Immunoprecipitation plus lectin blot was performed. Bars represented mean \pm SD of three independent tests, all $* \mathrm{P}<0.05$. WCL, whole cell lysate.

\section{Glycosylation of CD147 is involved in $\beta 3 G n T 8$ mediated gastric cancer cell invasion}

CD147 is a glycoprotein that carries polylactosamine sugars on its $\mathrm{N}$-glycosylation sites [18]. To further investigate if $\beta 3 \mathrm{GnT} 8$ could affect CD147 glycosylation in gastric cancer cells, firstly, we analyzed the effect of $\beta 3 \mathrm{GnT} 8$ on the synthesis of total polylactosamine chains. The results showed that knockdown of $\beta 3 \mathrm{GnT} 8$ in AGS cells dramatically decreased total polylactosamine levels (Figure 4A). Conversely, polylactosamines were increased after ectopic expression of $\beta 3 \mathrm{GnT} 8$ in NCI-N87 cells. Lectin blot analysis revealed that the polylactosamine units on glycoproteins were also altered by different $33 \mathrm{GnT}$ 8 levels (Figure 4B). Lectin blot analysis showed the consistent alteration of glycan structures with flow cytometry assay.

Furthermore, we observed that high glycosylated (HG)-CD147 was markedly increased by over-expression of $\beta 3 \mathrm{GnT} 8$ in NCI-N87 cells (Figure $4 \mathrm{C})$. Inversely, the expression of HG-CD147 was reduced when $\beta 3 \mathrm{GnT} 8$ was down-regulated in AGS cells. After the IP with anti-CD147 antibody, lectin blot assay from total cell lysate protein revealed the similar results (Figure 4D). These data indicated that the regulated $\beta 3 \mathrm{GnT} 8$ converted the heterogeneous $\mathrm{N}$-glycosylated forms of CD147 in gastric cancer cells, and significantly changed the polylactosamine structures on CD147.

\section{Identification of interaction partners of $\beta 3 \mathrm{GnT} 8$ in gastric cancer cells by proteomic analysis}

To explore the mechanism underlying B3GnT8-mediated glycosylation of CD147 in gastric cancer cells, a proteomic approach by IP of $\beta 3 \mathrm{GnT} 8$ followed by Nano-HPLC and LC-MS/MS analysis was applied. And a negative control using serum IgG was used to distinguish non-specifically bound proteins. We thereby identified total of 9 proteins from the analyses, which were immunoprecipitated together with $33 \mathrm{GnT} 8$ but not with the control. Table 2 shows the most abundant hits also indicating the number of biological repeats in AGS and NCI-N87 cells. A careful review of the literature revealed that there exist interaction effects between ANXA2 and CD147 [19]. As expected, we found that ANXA2 specifically bound to CD147 in gastric cancer cells (Figure 5A). We therefore selected ANXA2 as a candidate molecule.

In order to validate the interaction between ANXA2 and $33 \mathrm{GnT}$, we undertook co-IP assay. Protein expression of ANXA2 in AGS and NCI-N87 cells was detected by western blot. As shown in 
Figure $5 \mathrm{~B}$, the expression of ANXA2 was much higher in AGS cells than that in NCI-N87 cells. ANXA2 was then found to co-immunoprecipitate with $\beta 3 \mathrm{GnT} 8$ in AGS and NCI-N87, indicating that ANXA2 and $\beta 3 \mathrm{GnT}$ 8 interact in their native form in gastric cancer cells (Figure 5C). However, directly binding between the CD147 and $33 \mathrm{GnT} 8$ was not found in this study. ANXA2 and $\beta 3$ GnT8 may act as a functional complex, which plays an important role in CD147 glycosylation.

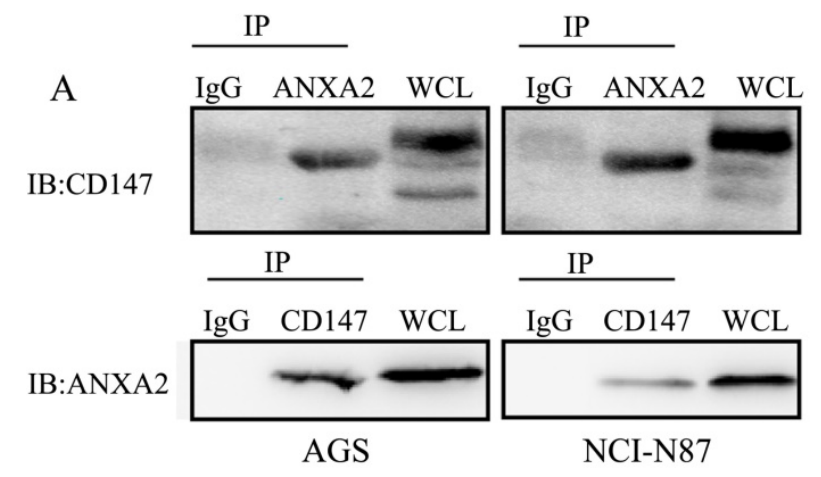

B

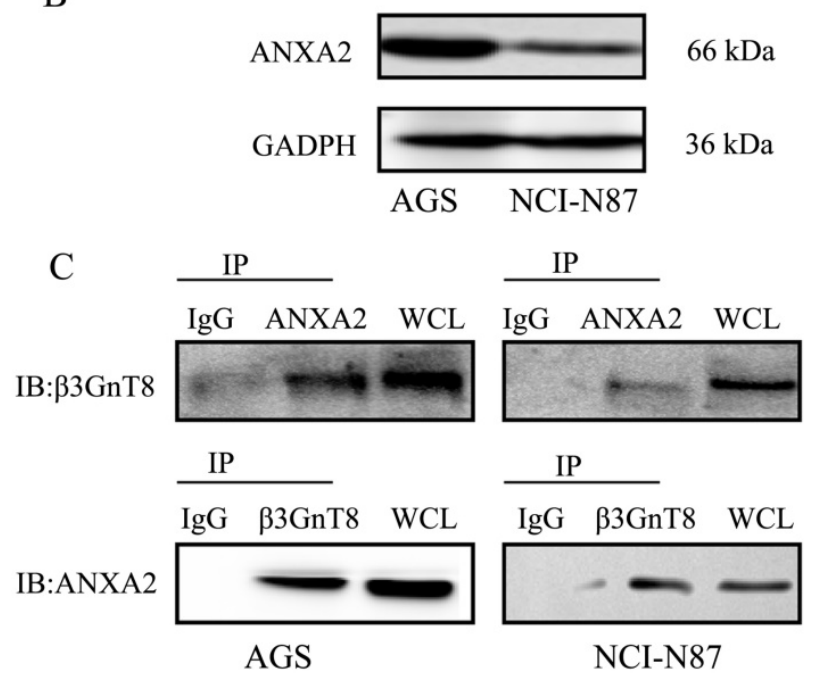

Figure 5. Co-immunoprecipitation of $\beta 3 \mathrm{GnT} 8$ and $A N X A 2$ in gastric cancer cells. (A) CD147 immunoprecipitated with ANXA2 in NCl-N87 and AGS cells. (B) The protein expression of ANXA2 was detected by western blot in NCl-N87 and AGS cells. (C) $33 \mathrm{GnT8}$ immunoprecipitated with ANXA2 in NCl-N87 and AGS cells. Serum IgG was used as a negative control.

\section{Discussion}

Glycosylation controls diverse protein functions and regulates various cellular phenotypes. Alterations in cell surface glycosylation are believed to play crucial roles in tumor progression, metastasis, and therapeutics[20]. Recent studies reveal that decreased core-fucosylation of N-glycans [21, 22] and reduced gland mucin-specific O-glycans [23] contribute to malignancy in gastric cancer. Identifying these biomarkers could provide new insights for understanding the mechanisms of gastric cancer invasion, and designing better therapeutic strategies. $\beta 3 \mathrm{GnT}$ 8 transfers GlcNAc to the non-reducing terminus of the Gal $\beta 1-4 \mathrm{GlcNAc}$ of tetra-antennary $\mathrm{N}$-glycan to form polylactosamine structures [5]. As $33 \mathrm{GnT}$ 8 expression was associated with aggressive tumor phenotype, we identified and functionally characterized $\beta 3 \mathrm{GnT} 8$ as an important regulator in gastric cancer invasion. In addition, it provides a potential therapeutic target for the future treatment of gastric cancer.

Table 2. Identification of potential interaction partners of B3GnT8 by LC-MS/MS analysis in different gastric cancer cells

\begin{tabular}{lllll}
\hline Protein & Description & $\begin{array}{l}\text { Uniprot } \\
\text { accession } \\
\text { number }\end{array}$ & $\begin{array}{l}\text { AGS } \\
\text { a }\end{array}$ & NCI-N87 a \\
\hline ACTB & Actin, cytoplasmic 1 & P60709 & 18 & 19 \\
JUP & Junction plakoglobin & P14923 & 23 & 13 \\
DCD & Dermcidin & P81605 & 12 & 16 \\
ANXA2 & Annexin A2 & P07355 & 22 & 29 \\
PIP & Prolactin-inducible protein & P12273 & 21 & 27 \\
HRNR & Hornerin & Q86YZ3 & 8 & 5 \\
TET1 & Methylcytosine dioxygenase & Q8NFU7 & 17 & 14 \\
& TET1 & & & 2 \\
AGPAT1 & 1-acyl-sn-glycerol-3-phosphate Q99943 & 4 & 2 \\
& acyltransferase alpha & & & 3 \\
HSPD1 & Heat shock 60kDa protein 1 & P10809 & 2 & 3
\end{tabular}

a Number of unique peptides identified.

Polylactosamine, which can be incorporated into both N- and O-linked glycans, is a unique glycan composed of repeating $\mathrm{N}$-acetyllactosamine units[24]. This polymers carried on N-glycans are believed to aid metastasis by making the cells more invasive [25-27]. Inhibition of polylactosamines using different strategies always results in the loss of the metastatic ability. Conversely, induction of their expression has been shown to result in acquisition of the metastatic phenotype. Lectin staining with LEL, which recognizes polylactosamines, was undertaken to obtain expression profiles of these structures[28, 29]. In the present study, we showed that polylactosamine chains were significantly up-regulated in gastric cancer tissues compared with the adjacent non-cancerous tissues. Moreover, polylactosamine levels were significantly correlated with aggressive tumor characteristics (lymph node metastasis and TNM stage). We also confirmed that the expression levels of $\beta 3 \mathrm{GnT} 8$ were positively correlated with polylactosamines expression in gastric cancer tissues and cell lines. Over-expression and knockdown of 33 GnT8 could markedly increase and reduce polylactosamines in gastric cancer cells. To our knowledge, this is the first report on the role of polylactosamines in gastric cancer progression. 
However, to further confirm the functions of $\beta 3 \mathrm{GnT}$ 8 and polylactosamines, a larger number of gastric cancer samples than available would be required.

In addition, we explored the mechanisms behind the association between $\beta 3 \mathrm{GnT} 8$ and gastric cancer metastasis and identified downstream effectors contributing to this process. CD147, a cell surface transmembrane glycoprotein, has been reported to be correlated with gastric cancer aggressiveness. For example, CD147 expression was associated with gastric cancer invasion, metastasis and TNM stage [30]. Up-regulated CD147 could enhance gastric cancer cell invasion and angiogenesis [31]. Because of the heterogeneous N-glycosylation, CD147 shows both high glycosylated (HG)-CD147 ( 40-60 kDa), and a low glycosylated (LG) -CD147 ( 32 kDa) form[32]. Elevated glycosylation of CD147, yielding HG-CD147, is attributable to high polylactosamine content [33]. Our results showed that knockdown of $\beta 3$ GnT8 could efficiently inhibit HG-CD147 in AGS cells. In contrast, up-regulation of $\beta 3 \mathrm{GnT} 8$ significantly enhanced HG-CD147 expression in NCI-N87 cells. 33 GnT8 associates with HG-CD147 and enhances the biosynthetic conversion of LG-CD147 to HG-CD147. This is in line with our previous study that $\beta 3 \mathrm{GnT} 8$ could regulate the metastatic potential of colorectal cancer cells by altering the glycosylation of CD147[8]. It is so far not well understood how these processes are regulated and which interaction partners are involved.

We performed a proteomic screen for investigation of the interactome of $\beta 3 \mathrm{GnT} 8$ in gastric cancer cells. We thereby identified a number of interaction proteins. We confirmed ANXA2 as a general binding partner for $\beta 3 \mathrm{GnT} 8$ by co-IP assay. ANXA2 is a calcium-dependent phospholipid binding protein that is mainly located on the cell membrane[34]. Its aberrant expression enhanced the malignant properties of cancer cells[35]. Up-regulated ANXA2 was associated with lymph node metastasis, advanced TNM stage in patients with gastric cancer[36, 37]. Here, we found that AGS cells expressed more ANXA2 protein than NCI-N87 cells. Changes in the expression of ANXA2 were closely associated with the invasion phenotype of different gastric cancer cell. $\beta 3 \mathrm{GnT} 8$ and ANXA2 may act as a functional complex during the invasion and migration of gastric cancer cells.

Recent studies have revealed that ANXA2 and CD147 interact with each other in the same signal transduction pathway[19]. ANXA2 was found to be co-localized and co-immunoprecipitated with CD147 in hepatocellular carcinoma cells[38, 39]. In this study, the two molecules were also found to co-immunoprecipitate with each other in gastric cancer cells. According to our data, we suggest that ANXA2 might act as a linker between CD147 and $\beta 3 \mathrm{GnT} 8$, and then regulate $\beta 3 \mathrm{GnT} 8$-induced glycosylation of CD147.

In conclusion, our data highlight the molecular etiology and clinical significance of $\beta 3 \mathrm{GnT}$ \% in gastric cancer. $\beta 3 \mathrm{GnT} 8$ promotes gastric cancer cell migration and invasion by functionally converting the polylactosamine chains carried on CD147. ANXA2 is an essential interaction partner of $\beta 3 \mathrm{GnT} 8$ during CD147 glycosylation. Thus, targeting $\beta 3 \mathrm{GnT} 8$ may represent a new therapeutic strategy for the treatment of gastric cancer patients.

\section{Acknowledgements}

The present study was supported by the Natural Science Foundation of Hubei Provincial Department of Education (Q20162115), Innovative Research Team of Hubei University of Medicine (2014CXG02), and the Scientific and Technological Project of Shiyan City of Hubei Province (15K65).

\section{Competing Interests}

The authors have declared that no competing interest exists.

\section{References}

1. Torre LA, Bray F, Siegel RL, et al. Global cancer statistics, 2012. CA: a cancer journal for clinicians. 2015; 65: 87-108.

2. Wang J, Yu JC, Kang WM, et al. Treatment strategy for early gastric cancer. Surg Oncol. 2012; 21: 119-23.

3. Yan W, Wu K, Herman JG, et al. Epigenetic silencing of DACH1 induces the invasion and metastasis of gastric cancer by activating TGF-beta signalling. Journal of cellular and molecular medicine. 2014; 18: 2499-511.

4. Hu L, Duan YT, Li JF, et al. Biglycan enhances gastric cancer invasion by activating FAK signaling pathway. Oncotarget. 2014; 5: 1885-96.

5. Ishida $\mathrm{H}$, Togayachi $\mathrm{A}$, Sakai $\mathrm{T}$, et al. $\mathrm{A}$ novel beta1,3-N-acetylglucosaminyltransferase (beta3Gn-T8), which synthesizes poly-N-acetyllactosamine, is dramatically upregulated in colon cancer. FEBS Lett. 2005; 579: 71-8.

6. Huang $\mathrm{C}, \mathrm{Zhou} \mathrm{J}$, Wu S, et al. Cloning and tissue distribution of the human B3GALT7 gene, a member of the beta1,3-Glycosyltransferase family. Glycoconjugate journal. 2004; 21: 267-73.

7. Jiang Z, Ge Y, Zhou J, et al. Subcellular localization and tumor distribution of human beta3-galactosyltransferase by beta3GalT7 antiserum. Hybridoma (Larchmt). 2010; 29: 141-6.

8. Ni J, Jiang Z, Shen L, et al. beta3GnT8 regulates the metastatic potential of colorectal carcinoma cells by altering the glycosylation of CD147. Oncol Rep. 2014; 31: 1795-801.

9. Liu J, Shen L, Yang L, et al. High expression of beta3GnT8 is associated with the metastatic potential of human glioma. Int J Mol Med. 2014; 33: 1459-68.

10. Shen L, Liu Z, Tu Y, et al. Regulation of MMP-2 expression and activity by beta-1,3-N-acetylglucosaminyltransferase- 8 in AGS gastric cancer cells. Mol Biol Rep. 2011; 38: 1541-50.

11. Jiang Z, Hu S, Hua D, et al. beta3GnT8 plays an important role in CD147 signal transduction as an upstream modulator of MMP production in tumor cells. Oncol Rep. 2014; 32: 1156-62.

12. Yang GZ, Hu L, Cai J, et al. Prognostic value of carbonic anhydrase VII expression in colorectal carcinoma. BMC Cancer. 2015; 15: 209.

13. Chavez JD, Schweppe DK, Eng JK, et al. Quantitative interactome analysis reveals a chemoresistant edgotype. Nature communications. 2015; 6: 7928.

14. Han Y, Yu G, Sarioglu H, et al. Proteomic investigation of the interactome of FMNL1 in hematopoietic cells unveils a role in calcium-dependent membrane plasticity. Journal of proteomics. 2013; 78: 72-82.

15. Hofmann BT, Schluter L, Lange $\mathrm{P}$, et al. COSMC knockdown mediated aberrant O-glycosylation promotes oncogenic properties in pancreatic cancer. Mol Cancer. 2015; 14: 109.

16. Blount AL, Schmidt $\mathrm{K}$, Justice NJ, et al. FoxL2 and Smad3 coordinately regulate follistatin gene transcription. The Journal of biological chemistry. 2009; 284 : 7631-45. 
17. Seko A, Yamashita K. Activation of beta1,3-N-acetylglucosaminyltransferase-2 (beta3Gn-T2) by beta3Gn-T8. Possible involvement of beta3Gn-T8 in increasing poly-N-acetyllactosamine chains in differentiated HL-60 cells. The Journal of biological chemistry. 2008; 283: 33094-100.

18. Huang W, Luo WJ, Zhu P, et al. Modulation of CD147-induced matrix metalloproteinase activity: role of CD147 N-glycosylation. The Biochemical journal. 2013; 449: 437-48.

19. Zhao P, Zhang W, Tang J, et al. Annexin II promotes invasion and migration of human hepatocellular carcinoma cells in vitro via its interaction with HAb18G/CD147. Cancer science. 2010; 101: 387-95.

20. Taniguchi N, Kizuka Y. Glycans and cancer: role of N-glycans in cancer biomarker, progression and metastasis, and therapeutics. Advances in cancer research. 2015; 126: 11-51.

21. Zhao YP, Xu XY, Fang M, et al. Decreased core-fucosylation contributes to malignancy in gastric cancer. PLoS ONE. 2014; 9: e94536.

22. Liu L, Yan B, Huang J, et al. The identification and characterization of novel N-glycan-based biomarkers in gastric cancer. PLoS ONE. 2013; 8: e77821.

23. Shiratsu K, Higuchi K, Nakayama J. Loss of gastric gland mucin-specific O-glycan is associated with progression of differentiated-type adenocarcinoma of the stomach. Cancer science. 2014; 105: 126-33.

24. Henion TR, Schwarting GA. N-linked polylactosamine glycan synthesis is regulated by co-expression of beta3GnT2 and GCNT2. J Cell Physiol. 2014; 229: 471-8.

25. Saitoh O, Wang WC, Lotan R, et al. Differential glycosylation and cell surface expression of lysosomal membrane glycoproteins in sublines of a human colon cancer exhibiting distinct metastatic potentials. The Journal of biological chemistry. 1992; 267: 5700-11.

26. Srinivasan N, Bane SM, Ahire SD, et al. Poly N-acetyllactosamine substitutions on $\mathrm{N}$ - and not $\mathrm{O}$-oligosaccharides or Thomsen-Friedenreich antigen facilitate lung specific metastasis of melanoma cells via galectin-3. Glycoconjugate journal. 2009; 26: 445-56.

27. Krishnan V, Bane SM, Kawle PD, et al. Altered melanoma cell surface glycosylation mediates organ specific adhesion and metastasis via lectin receptors on the lung vascular endothelium. Clinical \& experimental metastasis. 2005; 22: 11-24.

28. Shen $\mathrm{L}, \mathrm{Yu} \mathrm{M}, \mathrm{Xu}$ X, et al. Knockdown of beta3GnT8 reverses 5-fluorouracil resistance in human colorectal cancer cells via inhibition the biosynthesis of polylactosamine-type N-glycans. International journal of oncology. 2014; 45: 2560-8.

29. Togayachi A, Kozono Y, Ishida H, et al. Polylactosamine on glycoproteins influences basal levels of lymphocyte and macrophage activation. Proc Natl Acad Sci U S A. 2007; 104: 15829-34.

30. Chu D, Zhu S, Li J, et al. CD147 expression in human gastric cancer is associated with tumor recurrence and prognosis. PloS one. 2014; 9: e101027.

31. Zheng HC, Takahashi $\mathrm{H}$, Murai $\mathrm{Y}$, et al. Upregulated EMMPRIN/CD147 might contribute to growth and angiogenesis of gastric carcinoma: a good marker for local invasion and prognosis. British journal of cancer. 2006; 95: 1371-8.

32. Fan J, Wang S, Yu S, et al. N-acetylglucosaminyltransferase IVa regulates metastatic potential of mouse hepatocarcinoma cells through glycosylation of CD147. Glycoconjugate journal. 2012; 29: 323-34.

33. Tang W, Chang SB, Hemler ME. Links between CD147 function, glycosylation, and caveolin-1. Molecular biology of the cell. 2004; 15: 4043-50.

34. Zhuang $\mathrm{H}$, Tan M, Liu J, et al. Human epididymis protein 4 in association with Annexin II promotes invasion and metastasis of ovarian cancer cells. Molecular cancer. 2014; 13: 243.

35. Xing $\mathrm{R}, \mathrm{He} \mathrm{H}, \mathrm{He} \mathrm{Y}$, et al. ANXA2 remodels the microstructures of caco2 cells. Cell Mol Biol (Noisy-le-grand). 2013; 59 (Suppl): OL1848-54.

36. Han Y, Ye J, Dong Y, et al. Expression and significance of annexin A2 in patients with gastric adenocarcinoma and the association with E-cadherin. Experimental and therapeutic medicine. 2015; 10: 549-54.

37. Emoto $\mathrm{K}$, Sawada $\mathrm{H}$, Yamada $\mathrm{Y}$, et al. Annexin II overexpression is correlated with poor prognosis in human gastric carcinoma. Anticancer research. 2001; 21: $1339-45$.

38. Zhang $\mathrm{W}$, Zhao $\mathrm{P}, \mathrm{Xu} \mathrm{XL}$, et al. Annexin $\mathrm{A} 2$ promotes the migration and invasion of human hepatocellular carcinoma cells in vitro by regulating the shedding of CD147-harboring microvesicles from tumor cells. PloS one. 2013; 8: e67268.

39. Zhao $\mathrm{P}$, Zhang $\mathrm{W}$, Wang SJ, et al. HAb18G/CD147 promotes cell motility by regulating annexin II-activated RhoA and Rac1 signaling pathways in hepatocellular carcinoma cells. Hepatology. 2011; 54: 2012-24. 